\title{
An evidence-based review of recent advances in therapy for heart failure with reduced ejection fraction (HFrEF)
}

\author{
Leah Raj, ${ }_{1}^{1}$ Bhavin Adhyaru ${ }^{2}$
}

\begin{abstract}
'Department of Medicine, Emory University School of Medicine, Atlanta, Georgia, USA

${ }^{2}$ Division of General Internal Medicine \& Geriatrics, Department of Medicine, Emory University School of Medicine, Atlanta, Georgia, USA
\end{abstract}

\section{Correspondence to} Dr Leah Raj, Department of Medicine, Emory University School of Medicine, 49 Jesse Hill Jr. Drive, Atlanta, GA 30303, USA; Iraj@emory.edu

Received 15 July 2016 Revised 3 September 2016 Accepted 13 September 2016 Published Online First 5 October 2016

\section{CrossMark}

To cite: Raj L, Adhyaru B. Postgrad Med J

2016:92:726-734

\section{ABSTRACT}

An estimated 5.1 million Americans have chronic heart failure and this is expected to increase $25 \%$ by 2030 . Heart failure is a clinical syndrome that evolves from either functional or structural changes to the ventricles that lead to filling or ejection abnormalities. Thus far, pharmacotherapy has been show to be beneficial in patients only with reduced ejection fraction; however, new therapies have been developed in hopes of reducing the burden of heart failure. In this review, we will discuss current pharmacotherapies recommended in American College of Cardiology/American Heart Association guidelines, the evidence behind these recommendations as well as new and emerging therapies that have been developed.

\section{BACKGROUND AND PATHOPHYSIOLOGY}

An estimated 5.1 million Americans have heart failure and this is expected to increase $25 \%$ by 2030. ${ }^{1}$ This results in nearly 1 million hospital admissions yearly due to heart failure. ${ }^{2}$ In 2014, $23 \%$ of heart failure-related deaths labelled heart failure as the underlying cause. ${ }^{3}$

Heart failure is a clinical syndrome that evolves from either functional or structural changes to the ventricles that lead to filling or ejection abnormalities. ${ }^{4}$ Disorders of the pericardium, myocardium, endocardium, heart valves or vessels can precede these changes; however, most commonly impaired left ventricular myocardial function is the culprit. Heart failure can be subdivided based on ejection fraction (EF). However, it is important to note that systolic and diastolic dysfunction can co-exist in both these groups. Heart failure with reduced ejection fraction (HFrEF) describes patients with a dilated left ventricle (LV) and EF $<40 \%{ }^{4}$ In contrast, heart failure with preserved ejection fraction (HFpEF) indicates patients have EF $>50 \%$ and a normal LV size. In the most recent update to the American College of Cardiology (ACC)/American Heart Association (AHA) heart failure guidelines, $\mathrm{HFpEF}$ is further subdivided into borderline (EF 41\%-49\%) and improved (EF >40\%). ${ }^{4}$ However, there are few studies that evaluate pharmacotherapies in these populations. For the purpose of this review, we will focus on HFrEF.

Several mechanisms contribute to the development of heart failure. Neurohormonal activation, endothelial dysfunction, venous congestion and myocardial remodelling are just a few that can be named. In the early stages of heart failure, neurohormonal activation, such as the reninangiotensin-aldosterone system (RAAS) enhances cardiac contractility, sodium and fluid retention and peripheral vasoconstriction in attempts to provide perfusion to organs. ${ }^{5}{ }^{6}$ Despite initial benefits, over time these mechanisms lead to cardiac dysfunction and remodelling by fibroblast proliferation, oxidative stress and extracellular matrix deposition resulting in apoptosis and fibrosis. ${ }^{5}$ Venous congestion, either from progressive volume overload or rapid fluid shifts that induce the sympathetic system also lead to neurohormonal activation and its downstream effects. ${ }^{7} 8$ Vascular endothelium produces and metabolises nitric oxide. Along with cytokines and prostaglandins, nitric oxide alters myocardial function, haemodynamics and coronary and renal circulation. ${ }^{9}$

Some of the strongest predictors of decompensated heart failure include the presence of orthopnoea, paroxysmal nocturnal dyspnoea (PND), presence of an S3, evidence of jugular venous distension (JVD) or hepatojugular reflux, chest X-ray suggestive of oedema, and B-type natriuretic peptide $(\mathrm{BNP})>250 \mathrm{pg} / \mathrm{mL}$. Table 1 describes the sensitivity and specificity of many findings seen in decompensated heart failure.

The Framingham clinical criteria uses symptoms such as orthopnoea, paroxysmal nocturnal and elevated jugular venous pressure by requiring at least two major or one major and two minor criteria to diagnose heart failure (table 2). Apart from history and clinical signs and symptoms, imaging such as ECG, chest X-ray and transthoracic echocardiography can aid in diagnosis of heart failure.

Laboratory data are a vital component to diagnose heart failure. For example, elevated blood levels of BNP or N-terminal pro-B-type natriuretic peptide (NT-proBNP) are commonly elevated in heart failure. When the ventricular myocytes are under stress, they secrete prohormone pre-proBNP, which is cleaved into BNP and NT-proBNP. Secretion of these peptides induces vasodilation, diuresis and inhibits renin and aldosterone production. ${ }^{12}$ Decompensated heart failure is just one of many cardiac, as well as, non-cardiac disorders where elevated levels have been detected, such as sepsis, infiltrative diseases, cirrhosis, pulmonary embolism or renal failure. ${ }^{12}$

Natriuretic peptides have good prognostic implications. Elevated BNP has been associated with increased mortality and cardiovascular events in all patients with heart failure. ${ }^{13}$ In fact, in hospital mortality is higher in patients admitted for decompensated heart failure with a BNP $>1730 \mathrm{pg} / \mathrm{mL}$ compared with those with BNP $<430 \mathrm{pg} / \mathrm{mL}^{14}$ 
Table 1 Signs and symptoms of heart failure classified by sensitivity and specificity ${ }^{10}$

\begin{tabular}{lllll}
\hline Sign/symptom & $\begin{array}{l}\text { Sensitivity } \\
(\%)\end{array}$ & $\begin{array}{l}\text { Specificity } \\
(\%)\end{array}$ & $\begin{array}{c}\text { LR } \\
(+)\end{array}$ & $\begin{array}{c}\text { LR } \\
(-)\end{array}$ \\
\hline $\begin{array}{l}\text { History of myocardial } \\
\text { infarction }\end{array}$ & 60 & 86 & 4.4 & 0.45 \\
PND & 41 & & 2.6 & 0.70 \\
Orthopnoea & 50 & 84 & 2.2 & 0.65 \\
Oedema & 51 & 77 & 2.1 & 0.64 \\
Dyspnoea on exertion & 84 & 76 & 1.3 & 0.48 \\
S3 & 13 & 34 & 11 & 0.88 \\
Hepatojugular reflux & 24 & 99 & 6.4 & 0.79 \\
JVD & 39 & 96 & 5.1 & 0.66 \\
Lower extremity oedema & 50 & 92 & 2.8 & 0.51 \\
Chest X-ray findings of & 54 & 78 & 12 & 0.48 \\
pulmonary congestion & & 96 & 3.8 & 0.79 \\
ECG findings of atrial & 26 & 93 & 4.6 & 0.14 \\
fibrillation & & & & \\
BNP $\geq 250$ pg/mL & 89 & 81 & & \\
\hline BNP, B-type natriuretic peptide; JVD, jugular venous distension; PND, paroxysmal \\
nocturnal dyspnoea.
\end{tabular}

Finally, BNP has also been evaluated in attempts to guide therapy based on its value, but results have been controversial. In one systematic review, patients with heart failure were treated based on BNP or clinical-guided therapy. In the cohort where treatment was based on BNP, it showed decreased hospitalisation due to heart failure, decreased cardiovascular disease and decreased all-cause mortality in patients aged $<75$ years. ${ }^{15}$ Currently, the ongoing PRIMA II trial is the first randomised clinical trial to investigate the impact of NT-proBNP-guided therapy during admission for acute heart failure on clinical outcomes as heart failure readmission and mortality rates. Interestingly, obesity can cause the BNP to be falsely low. In patients with a body mass index (BMI) $>40$, the BNP cut-off should be $<100 \mathrm{pg} / \mathrm{mL}$ to rule out heart failure compared with 100 in a general population. ${ }^{16}$

Heart failure can be classified according to either symptoms or evolution of the disease. The New York Heart Association (NYHA) functional classification assigns patients to one of four classes based on the effort needed to elicit clinical symptoms (table 3).

In comparison, the ACC/AHA heart failure stages emphasise the progressive development of heart failure and recognise risk

Table 2 Modified Framingham clinical criteria ${ }^{11}$

\begin{tabular}{|c|c|}
\hline Major criteria & Minor criteria \\
\hline Paroxysmal nocturnal dyspnoea & Bilateral leg oedema \\
\hline Orthopnoea & Nocturnal cough \\
\hline Elevated jugular venous pressure & $\begin{array}{l}\text { Dyspnoea on ordinary } \\
\text { exertion }\end{array}$ \\
\hline Pulmonary rales & Hepatomegaly \\
\hline S3 & Pleural effusion \\
\hline Cardiomegaly on chest X-ray & $\begin{array}{l}\text { Tachycardia (heart rate } \\
\geq 120 \mathrm{bpm} \text { ) }\end{array}$ \\
\hline Pulmonary oedema on chest X-ray & $\begin{array}{l}\text { Weight loss } \geq 4.5 \mathrm{~kg} \text { in } \\
5 \text { days }\end{array}$ \\
\hline $\begin{array}{l}\text { Weight loss } \geq 4.5 \mathrm{~kg} \text { in } 5 \text { days after medical } \\
\text { treatment for heart failure }\end{array}$ & \\
\hline
\end{tabular}

Table 3 New York Heart Association functional classification of heart failure ${ }^{4}$

\begin{tabular}{ll}
\hline Class I & $\begin{array}{l}\text { Symptoms of heart failure only at levels that would limit } \\
\text { normal individuals }\end{array}$ \\
Class II & $\begin{array}{l}\text { Symptoms of heart failure on ordinary exertion } \\
\text { Class III }\end{array}$ \\
Class IV & Symptoms of heart failure on less-than-ordinary exertion \\
\hline
\end{tabular}

factors and predisposition to the disease (table 4). Unlike the NYHA classification that can change depending on patient's symptoms, the ACC/AHA classification is fixed and cannot be reversed.

Currently, the recommendations for treatment of stages A and $\mathrm{B}$ focuses on risk factor modification and treatment of atherosclerotic cardiovascular disease (ASCVD). The focus of this review will be on patients with chronic HFrEF who fall in stage $\mathrm{C}$ of disease.

\section{LIFESTYLE MODIFICATIONS}

Recommendations for lifestyle modification are based on data from observational studies as there are limited randomised trials exploring its effects. However, most patients are instructed to abstain from smoking, alcohol consumption and obesity. Most recently, it has been shown that overweight and obesity are associated with increased risk of heart failure. Specifically, a BMI $>23$ is associated with an increased incidence. ${ }^{17}$ Salt restriction is most commonly recommended; however, the ACC/AHA guidelines from 2013 merely state, "sodium restriction is reasonable for patients with symptomatic heart failure to reduce congestive symptoms". ${ }^{4}$ Similarly, fluid restriction of $1.5-2 \mathrm{~L}$ is regarded as reasonable for stage D patients. ${ }^{4}$ Given the rationale that fluid retention leads to increased weight, daily weight monitoring is suggested for this patient population to prevent rehospitalisation.

\section{Cardiac rehabilitation}

Exercise in patients with heart failure has been proven to be safe. In fact, cardiac rehabilitation has been proven to reduce mortality, rehospitalisations and clinical symptoms in patients with $\mathrm{HFrEF}$ and is recommended for all patients who are able to participate. ${ }^{18} 19$

\section{PHARMACOLOGICAL THERAPY}

There are many drugs available to treat HFrEF that either improves mortality or morbidity. In the past 5 years, there are several new classes of drugs with promising benefit. Table 5 summarises the pharmacotherapy for treatment of heart failure with the evidence base for their use.

Table 4 American College of Cardiology/American Heart Association heart failure stage ${ }^{4}$

\begin{tabular}{ll}
\hline Stage A & $\begin{array}{l}\text { Patients who are at high risk for developing heart failure, but } \\
\text { have no structural disorder of the heart }\end{array}$ \\
Stage B & $\begin{array}{l}\text { Patients with structural disorders of the heart who have never } \\
\text { had symptoms of heart failure }\end{array}$ \\
Stage C & $\begin{array}{l}\text { Patients with past or current symptoms of heart failure } \\
\text { associated with underlying structural heart disease }\end{array}$ \\
Stage D & $\begin{array}{l}\text { Patients with end-stage disease who require specialised } \\
\text { treatment strategies }\end{array}$ \\
\hline
\end{tabular}


Table 5 Pharmacotherapy for treatment of HFrEF

\begin{tabular}{|c|c|c|c|c|c|c|}
\hline Pharmacotherapy & Evidence & Population & $\begin{array}{l}\text { Relative } \\
\text { risk (\%) }\end{array}$ & $\begin{array}{l}\text { Number } \\
\text { needed to } \\
\text { treat }\end{array}$ & $\begin{array}{l}2016 \text { ACC/AHA } \\
\text { guideline } \\
\text { recommendations }\end{array}$ & Special considerations \\
\hline ACEI/ARB & $\begin{array}{l}\text { CONSENSUS } \\
\text { SOLVD } \\
\text { Val-HeFT } \\
\text { VALIENT }\end{array}$ & $\begin{array}{l}\text { All patients with prior or current } \\
\text { symptoms of chronic HFrEF to reduce } \\
\text { morbidity and mortality }\end{array}$ & $11-27$ & $6.85-22$ & IA & $\begin{array}{l}\text { ARB can be recommended in } \\
\text { place of ACEI if patient is } \\
\text { intolerant to ACEI because of } \\
\text { cough or angiooedema }\end{array}$ \\
\hline$\beta$-Blocker & $\begin{array}{l}\text { MERIT-HF } \\
\text { COPERNICUS } \\
\text { Carvedilol HF } \\
\text { study } \\
\text { CIBIS I and II }\end{array}$ & $\begin{array}{l}\text { All patients with prior or current } \\
\text { symptoms of chronic HFrEF to reduce } \\
\text { morbidity and mortality }\end{array}$ & $19-65$ & $12-21$ & A & $\begin{array}{l}\text { Must be one of the following: } \\
\text { bisoprolol, carvedilol or } \\
\text { sustained-released metoprolol } \\
\text { succinate }\end{array}$ \\
\hline $\begin{array}{l}\text { Mineralocorticoid } \\
\text { receptor antagonist }\end{array}$ & $\begin{array}{l}\text { RALES } \\
\text { EMPHASIS-HF }\end{array}$ & $\begin{array}{l}\text { All patients with NYHA class II-IV } \\
\text { HFrEF to reduce morbidity and } \\
\text { mortality }\end{array}$ & $41-70$ & $8.8-9.4$ & IA & $\begin{array}{l}\text { Use only in patients with } \mathrm{Cr} \\
\leq 2.5 \mathrm{mg} / \mathrm{dL} \text { in men or } \mathrm{Cr} \\
\leq 2.0 \mathrm{mg} / \mathrm{dL} \text { in women and } \\
\text { potassium }<5.0 \mathrm{mEq} / \mathrm{L}\end{array}$ \\
\hline $\begin{array}{l}\text { Hydralazine-isosorbide } \\
\text { dinitrate }\end{array}$ & $\begin{array}{l}\text { V-HeFT } \\
\text { A-HeFT }\end{array}$ & $\begin{array}{l}\text { African-American patients with NYHA } \\
\text { class III-IV HFrEF already receiving } \\
\text { ACEI and } \beta \text {-blockers }\end{array}$ & 61 & 25 & IA & \\
\hline Aliskiren & $\begin{array}{l}\text { ASTRONAUT } \\
\text { ATMOSPHERE }\end{array}$ & & 5 & 59 & & $\begin{array}{l}\text { Not recommended by ACC/AHA } \\
\text { for treatment of heart failure }\end{array}$ \\
\hline Ivabradine & SHIFT & $\begin{array}{l}\text { Chronic symptomatic (NYHA class } \\
\text { II-III) stable HFrEF who are receiving } \\
\text { GDEM, including } \beta \text {-blocker at } \\
\text { maximum tolerated dose, and in NSR } \\
\text { with heart rate } \geq 70 \mathrm{bpm} \text { at rest }\end{array}$ & 23 & 21 & Ila B-R & \\
\hline Valsartan/Sacubitril & PARADIGM-HF & $\begin{array}{l}\text { Chronic symptomatic (NYHA class } \\
\text { II-III) HFrEF who tolerate an ACEI or } \\
\text { ARB, replaced by ARNI to reduce } \\
\text { morbidity and mortality }\end{array}$ & 20 & 20 & I B-R & $\begin{array}{l}\text { Do not administer concomitantly } \\
\text { with ACEI, within } 36 \text { hours of } \\
\text { last dose of ACEI, or to patients } \\
\text { with history of angiooedema }\end{array}$ \\
\hline \multicolumn{7}{|c|}{$\begin{array}{l}\text { ACCIAHA, American College of Cardiology/American Heart Association; ACEI, ACE inhibitor; A-HeFT, American Heart Failure; ASTRONAUT, Aliskiren Trial on Acute Heart Failure } \\
\text { Outcomes; ARB, angiotensin receptor blocker; ATMOSPHERE, Aliskiren Trial to Minimize Outcomes in Patients with Heart Failure; CIBIS, Cardiac Insufficiency Bisoprolol Study; } \\
\text { CONSENSUS, Cooperative North Scandinavian Enalapril Survival Study; COPERNICUS, Carvedilol Prospective Randomized Cumulative Survival Study Group; Cr, creatinine; EMPHASIS-HF, } \\
\text { Eplerenone in Mild Patients Hospitalized and Survival Study in Heart Failure; GDEM, guideline-directed evaluation and management; HFrEF, Heart Failure with Reduced Ejection Fraction; } \\
\text { MERIT-HF, Metoprolol CRIXL Randomized Intervention Trial in congestive heart failure; NSR, normal sinus rhythm; NYHA, New York Heart Association; PARADIGM-HF, Prospective } \\
\text { Comparison of ARNI with ACEI to Determine Impact on Global Mortality and Morbidity in Heart Failure; RALES, Randomized Aldactone Evaluation Study; SHIFT, Systolic Heart Failure } \\
\text { Treatment with the If inhibitor Ivabradine; SOLVD, Studies of Left Ventricular Dysfunction; Val-HeFT, Valsartan Heart Failure Trial; VALIENT, valsartan in Acute Myocardial Infarction Trial; } \\
\text { V-HeFT, Vasodilator Heart Failure. }\end{array}$} \\
\hline
\end{tabular}

\section{Known therapies for mortality benefit}

ACE inhibitor/angiotensin receptor blocker

One of the first randomised clinical trials proving ACE inhibitor (ACEI) has mortality benefits in systolic heart failure was the Cooperative North Scandinavian Enalapril Survival Study. It looked at the effects of enalapril in patients with NYHA class IV and showed a $40 \%$ relative risk reduction in mortality in patients treated with enalapril compared with the placebo group. ${ }^{20}$ There was also an improvement in NYHA classification, reduction of heart size and medication requirement. ${ }^{20}$ Since then, trials such as the Studies of Left Ventricular Dysfunction showed mortality benefits in patients with asymptomatic heart failure and reduced left ventricular ejection fraction (LVEF), broadening the population that would benefit from ACEI therapy. ${ }^{21}$ In an effort to inhibit RAAS at another step, valsartan, an angiotensin receptor blocker (ARB), was tested in the Valsartan Heart Failure Trial (Val-HeFT). Although, valsartan had no survival benefit, it was shown to reduce morbidity and improve clinical signs and symptoms in patients with heart failure NYHA class II-IV when added therapy that included ACEI, $\beta$-blockers, diuretics or digoxin. ${ }^{22}$ The Candesartan in Heart Failure-Assessment of Reduction in Mortality and Morbidity trial published after Val-HeFT showed that candesartan showed a similar benefit to enalapril. The Valsartan in Acute Myocardial Infarction trial looked at ACEI versus $A R B$ versus combination therapy and showed that ARB was non-inferior to ACEI and the combination group saw more adverse events. Current ACC/AHA guidelines recommend the use of ACEI (or ARB if patient cannot tolerate ACEI) in all patients with HFrEF. ${ }^{4}$

\section{$\beta$-Blockers}

$\beta$-Blockers have been the cornerstone of systolic heart failure therapy for decades. They have been shown to improve mortality and morbidity, decrease cardiac remodelling and reduce hospital admissions. However, only three $\beta$-blockers have been proven to have this effect. The first is sustained-release metoprolol succinate, a selective $\beta 1$-blocker, which showed a mortality benefit, reduced hospitalisations, improved NYHA functional class and quality of life in the Metoprolol CR/XL Randomized Intervention Trial in Congestive Heart Failure trial. ${ }^{23}$ The second $\beta$-blocker, carvedilol, a non-selective $\beta$-blocker and $\alpha$-blocker, had similar results in the Carvedilol Prospective Randomized Cumulative Survival Study Group and the Carvedilol Heart Failure Study. ${ }^{24} 25$ Finally, the Cardiac Insufficiency Bisoprolol Study (CIBIS) and CIBIS II trial demonstrated that bisoprilol, a selective $\beta 1$-blocker, reduced mortality and readmissions. $^{26} 27$ Therefore, these three selected $\beta$-blockers are recommended for all patients with current or prior symptoms of HFrEF. 4

More recently, the Study of Effects of Nebivolol Intervention on Outcomes and Rehospitalization in Seniors with Heart Failure looked at the effects of nebivolol in elderly patients with heart failure. It was shown the addition of nebivolol decreases all-cause mortality and cardiovascular hospital admissions in 
patients aged $>70$ years and currently not on $\beta$-blocker. However, this therapy is currently not recommended by ACC/AHA.

\section{Mineralocorticoid receptor antagonist}

In addition to ACEI and ARBs, aldosterone antagonists also inhibit steps of RAAS. The heart produces aldosterone in proportion to the severity of heart failure and also contains mineralocorticoid receptors (MCR). ${ }^{28}$ When the locally produced aldosterone works on the MCRs, this leads to stimulation of ACEI and RAAS. ${ }^{29}$ Using evidence from the Randomized Aldactone Evaluation Study and Eplerenone in Mild Patients Hospitalized and Survival Study in Heart Failure trial, current guidelines recommend addition of MCR antagonists to ACEI and $\beta$-blocker in patients with NYHA class II-IV and LVEF $<35 \%$ as well as those following acute myocardial infarction (MI) in patients with LVEF <40 who develop symptoms of heart failure or have history of diabetes mellitus. ${ }^{4}$ This medication should be avoided if patients have renal failure with creatinine $>2.0 \mathrm{mg} / \mathrm{dL}$ in men and $2.5 \mathrm{mg} / \mathrm{dL}$ in women and/or potassium $>5.0 \mathrm{mg} / \mathrm{dL}$.

\section{Hydralazine-isosorbide dinitrate}

Hydralazine is a smooth muscle relaxant that works on arteriolar dilation and cardiac afterload. Isosorbide dinitrate is a nitrate and venodilator, which improves cardiac preload. The combination of these drugs has proven to reduce mortality in patients with heart failure given their combined effort to reduce intracardiac filling pressures, which can reduce cardiac remodelling. In addition, hydralazine-nitrate therapy can enhance bioavailability of nitric oxide. ${ }^{30} 31$ The Vasodilator Heart Failure and African-American Heart Failure trials showed improved mortality compared with current medical management in a subset of patients, specifically African-Americans. Because of this, current guidelines indicate this combination therapy is recommended to reduce morbidity and mortality for African-American patients with NYHA class III-IV receiving optical medical therapy with ACEI and $\beta$-blockers. ${ }^{4}$

\section{Digoxin}

Digoxin has multiple actions in patients with heart failure including positive inotropy, reducing rapid ventricular rate, vasodilation, increasing baroreceptor sensitivity, reducing plasma neurohormones, increasing vagal tones and diuresis. ${ }^{32}$ By inhibiting Na-K-ATPase pump in myocardial cells, it leads to increased intracellular sodium and calcium concentrations, and eventually improved isolated myocyte contractions and left ventricular systolic function. ${ }^{33}{ }^{34}$ Several trials, most notably the Digitalis Investigation Group trial, have examined the efficacy of digoxin, comparing it with placebo, vasodilators and oral inotropic agents. All studies proved that it improved clinical symptoms, quality of life and lowered treatment failure rates; however, it did not improve survival. ${ }^{35}$ A newer medication, similar to digoxin, istaroxime, is being studied for heart failure benefit and the advantages include increased safety, improved contractility and less pro-arrhythmogenic than digoxin.

\section{Therapies targeting symptomatic relief} Diuretics

As stated, thousands of people are admitted every year for acute decompensated heart failure. In attempts to relieve their volume overload symptoms, they are treated with intravenous and oral diuretics. It has been shown that $90 \%$ of patients hospitalised with acute decompensated heart failure receive intravenous loop diuretics during the hospitalisation. ${ }^{36}$ Importantly, the Diuretic Optimization Strategies Evaluation trial proved that there were no significant differences is clinical symptoms comparing bolus and continuous infusions of intravenous furosemide. ${ }^{37}$ However, no study has proven any mortality of benefit when using diuretics and currently they are recommended solely for symptomatic relief. The available diuretics include furosemide, torsemide and bumetanide. The benefits of torsemide and bumetanide include increased oral bioavailability and metabolisation by the liver (compared with kidneys with furosemide). Of note, there are also some studies that suggest torsemide may reduce recurrent hospitalisations for decompensated heart failure compared with furosemide. ${ }^{38}$

\section{Inotropes}

Therapies such as left ventricular assist device (LVAD) or transplantation are mainstays of end-stage heart failure due to their ability to improve cardiac output. Inotropes also increase cardiac output, but do not exhibit the same long-term effect. Currently, milrinone and dobutamine are the only inotropes approved for use. They both increase intracellular level of cyclic AMP. ${ }^{39}$ Dobutamine is a sympathomimetic amine, which binds to $\beta 1, \beta 2$ and $\alpha 1$ adrenergic receptors. This leads to an inotropic effect, as well as a weak chronotropic effect. Specifically, $\alpha 1$ agonist activity leads to vasoconstriction balancing $\beta 2$ agonist vasodilatory effects, resulting in unchanged blood pressure. ${ }^{40}$ In contrast, milrinone is a phosphodiesterase-3 inhibitor that increases cardiac contractility and reduces afterload by altering left ventricular filling pressures.

Prolonged use of both inotropes can lead to inotrope dependence' defined by withdrawal leads to symptomatic hypotension, recurrent congestive symptoms or worsening renal function. ${ }^{41}$ Because of this, randomised clinical trials examining inotrope versus placebo have been ethically challenging and most data rely on retrospective analysis. ${ }^{42}$ The Evaluation Study of Congestive Heart Failure and Pulmonary Artery Catheterization Effectiveness trial evaluated 6-month mortality in patients with heart failure receiving inotropes reached $19 \%{ }^{43}$ More so, analysing the Acute Decompensated Heart Failure National Registry showed 200\% increase of in-hospital mortality in patients treated with inotropes compared with vasodilators. ${ }^{44}$

Most recent ACC/AHA guidelines from 2012 recommend inotropic agents in patients with stage D refractory to medical and device therapy who are waiting for LVAD or transplantation as bridge to therapy or palliative agent in symptomatic patients. ${ }^{4}$ It is also indicated as short-term support in patients with severe systolic dysfunction hospitalised presenting with low blood pressure at risk for end-organ damage. ${ }^{4}$

\section{New therapies}

Sacubitril/valsartan

In additional attempts to minimise the activation of RAAS and the natriuretic peptide system, sacubitril/valsartan was developed. It has two separate components. The first drug is valsartan, already known to block angiotensin type I. The second is a neprilysin inhibitor (NEPI) prodrug, sacubitril. This is converted to an enzyme that inhibits NEP and breaks down atrial natriuretic peptide (ANP), BNP and C-type natriuretic peptide. ${ }^{45}$ In addition, it has the ability to decrease vasoconstriction, sodium retention and maladaptive remodelling. ${ }^{46}$

This drug has the potential to inhibit two systems that lead to progression of heart failure. Some of the earlier trials evaluating NEPI compared with ACEI showed promise, but many had increased risk of angiooedema. A study evaluating NEPI and 
ACEI versus ACEI alone showed increased risk of angiooedema in the NEPI/ACEI group. ${ }^{47}$ As a result, the Prospective Comparison of ARNI with ACEI to Determine Impact on Global Mortality and Morbidity in Heart Failure evaluated an ARB/NEPI compared with ACEI. Inclusion criteria were NYHA class II-IV with EF $\leq 40 \%$, plasma $\mathrm{BNP} \geq 150$ or $\mathrm{BNP} \geq 100$, if the patient was hospitalised for heart failure within the past 12 months. The primary end point was the composite of cardiovascular mortality or hospitalisation for heart failure. In this prospective, double-blind, randomised trial, patients were randomly assigned to the sacubitril/ valsartan or enalapril. The study was stopped early given significant reductions in both primary end point and cardiovascular death. Sacubitril/valsartan reduced cardiovascular death or heart failure-related hospitalisation by $20 \%$ and all-cause mortality by $16 \%{ }^{48}$ Additionally, the risk of angiooedema was no different between the groups. However, there was a higher risk of symptomatic hypotension in the valsartan/sacubitril group. Recently, the Food and Drug Administration (FDA) approved this new therapy for heart failure treatment in patients with NYHA class II-IV with the goal of reducing mortality.

\section{Ivabradine}

Elevated heart rate is thought to contribute to increased morbidity and mortality in patients with heart failure. ${ }^{49} 50$ In patients with coronary artery disease and LV dysfunction, a heart rate of $70 \mathrm{bpm}$ or higher was associated with $34 \%$ increase of cardiovascular death and 53\% increase in admission to the hospital for heart failure compared with those patients with a heart rate $<70$ bpm. ${ }^{51}$ Tachycardia has also been shown to be a predictor of systolic function and therefore heart failure. ${ }^{52}$ Ivabradine selectively inhibits $I_{f}$ current in the sinoatrial node, which is partially responsible for pacemaker activity. By reducing sinoatrial node (SA) nodal discharge, this new drug is able to reduce the heart rate. ${ }^{53}$ Unlike $\beta$-blockers, which also reduce heart rate, it does not affect myocardial contractility or intracardiac conduction. ${ }^{54}$

In the Systolic Heart Failure Treatment with the If inhibitor Ivabradine trial, ivabradine was examined in addition to guideline-based treatment on cardiovascular outcomes, symptoms and quality of life in patients with chronic heart failure and systolic dysfunction. In this double-blind, placebocontrolled clinical trial, participants had moderate-to-severe heart failure, LV systolic dysfunction, resting heart rate $>70 \mathrm{bpm}$, recent hospitalisation for heart failure within the previous year and were on stable treatment including a $\beta$-blocker, if tolerated. Patients were randomly assigned to placebo or ivabradine. The primary end point was the composite of cardiovascular death or hospital admission for worsening heart failure. Study showed significant reduction in heart failure hospitalisations in the ivabradine arm compared with placebo $(16 \%$ vs $21 \%$ with $\mathrm{p}<0.0001)$. It also showed a $18 \%$ relative risk reduction in the primary end point and reduction in deaths due to heart failure in the ivabradine arm compared with placebo $(3 \%$ vs $5 \%$ with $\mathrm{p}<0.014) .{ }^{55}$ However, there were several problems with this trial including that not all patients were on $\beta$-blockers $(89 \%)$ and only $56 \%$ of patients were receiving $50 \%$ or more of the targeted $\beta$-blocker dose.

In April 2015, ivabradine was FDA approved for patients with chronic stable heart failure, with $\mathrm{EF}<35 \%$ who are unable to tolerate $\beta$-blockers or are on maximally tolerated $\beta$-blockers with a resting heart rate $>70 \mathrm{bpm}$.

\section{Aliskiren}

Val-HeFT study showed that there exists a relationship between plasma renin activity and subsequent major cardiovascular events in patients with systolic heart failure. ${ }^{56}$ Aliskiren is labelled as a direct renin inhibitor, but benefits include inhibiting all downstream effects of renin, including RAAS.

Aliskiren was investigated in the Aliskiren Trial on Acute Heart Failure Outcomes trial regarding reduction of rate of cardiovascular death or heart failure rehospitalisation among patients with heart failure. It was a double-blind, placebocontrolled study that randomised hospitalised patients with heart failure into aliskiren or placebo. Eligible patients included those with $\mathrm{EF}<40 \%$, elevated natriuretic peptides and signs and symptoms of fluid overload. The primary end point was measured as cardiovascular death or heart failure rehospitalisation at 6 or 12 months. It was found that initiation of aliskiren in addition to standard therapy did not reduce cardiovascular death or heart failure rehospitalisation at 6 or 12 months after discharge. ${ }^{57}$ Interestingly, a subgroup analysis showed that patients with diabetes and who received aliskiren had a higher risk of death compared with non-diabetics.

The recently published Aliskiren Trial to Minimize Outcomes in Patients with Heart Failure trial evaluated the role of aliskiren monotherapy compared with enalapril and combination therapy. The primary outcome was death from cardiovascular disease or hospitalisations for heart failure. The patients included had an average age of 63 , LVEF of $28 \%$ and about $30 \%$ of patients had diabetes mellitus. Over a follow-up period of 36.6 months, the authors did not show non-inferiority with aliskiren compared with enalapril and the combination group had more adverse events. ${ }^{58}$ Thus, the evidence is clear that the role for direct renin inhibition in heart failure is not clear for now.

\section{Other pharmacotherapies}

\section{Calcium-channel blockers}

There are two general categories of calcium-channel blockers (CCB) including the dihydropyridine (DHP) and nondihydropyridine (non-DHP). The DHP CCB class includes amlodipine, felodipine and nifedipine and the non-DHP CCB class includes diltiazem and verapamil. Most of the trials evaluating the non-DHP and first-generation DHP CCB have shown worse outcomes in heart failure, hence they should be avoided in patients with decompensated heart failure or chronic HFrEF as they have negative inotrope effect and can worsen heart failure symptoms. ${ }^{59}$

One randomised controlled trial (RCT), the Prospective Randomized Amlodipine Survival Evaluation trial, evaluated a second-generation non-DHP CCB, amlodipine. The outcome was combined risk of all-cause mortality and cardiovascular morbidity. The results showed a non-significant reduction (relative risk reduction $9 \%, \mathrm{p}=0.31$ ) in the primary outcome. ${ }^{60}$ As a result, current ACC recommendations state that $\mathrm{CCB}$ are not recommended as a routine treatment in patients with $\mathrm{HFrEF}$ and that non-DHP CCB should be avoided due to the negative inotrope effect.

\section{Anticoagulation}

Patients with HFrEF are at risk of having thromboembolic events given a hypokinetic LV and relative stasis of blood. However, the risk of a thromboembolic event is $1 \%-3 \%$ per year in this population. Several retrospective studies showed that the risk of embolic events was not lower in patients taking warfarin compared with placebo, but the risk of bleeding was much higher. The data on warfarin in reducing cardiovascular events and death in heart failure are mixed.

An RCT in 2009, the Warfarin and Antiplatelet therapy in Chronic Heart failure (WATCH) study compared aspirin, warfarin and clopidogrel for the primary outcome of all-cause mortality, non-fatal MI and non-fatal stroke. The results showed no 
statistical difference in superiority of either warfarin or clopidogrel to aspirin in the primary outcome. ${ }^{61}$ There was a significant reduction in non-fatal stroke in using warfarin.

Another RCT directly comparing warfarin with aspirin is the The Warfarin vs Aspirin in Reduced Cardiac Ejection Fraction trial (WARCEF). This RCT included 2305 patients randomised to warfarin or aspirin ( $325 \mathrm{mg}$ daily). The primary outcome was a composite of time to death, ischaemic stroke or intracerebral haemorrhage. The results showed a non-significant reduction in the composite outcome in the warfarin group, but a significant reduction in ischaemic stroke in the warfarin group similar to that seen in the WATCH study. ${ }^{62}$ However, there was also a higher risk of intracranial haemorrhage in the warfarin group.

A trial comparing clopidogrel with aspirin is currently ongoing. However, given the unclear evidence for aspirin or its dosing in the absence of coronary artery disease, it should likely not be used in heart failure. As a summary, the current guidelines do not recommend anticoagulation without known atrial fibrillation, a prior thromboembolic event or a cardioembolic source.

\section{Iron supplementation and erythropoietin therapy}

There has been much interest in the treatment of anaemia and its impact on heart failure. It has been associated with an increased risk in mortality in heart failure, decreased exercise capacity and impaired quality of life and increased risk for hospitalisation. ${ }^{63}$ There are two types of therapies that have been looked at: iron supplementation and erythropoietin-stimulating agents.

The Ferric Carboxymaltose Assessment in Patients with Iron Deficiency and Chronic Heart Failure With And Without Anemia trial evaluated the role of intravenous iron supplementation in heart failure. Interestingly in this trial, anaemia was not a requirement for inclusion and half the patients had a haemoglobin $(\mathrm{Hb})>12 \mathrm{~g} / \mathrm{dL}$. The patients enrolled had depressed left ventricular systolic function and NYHA class II-III and a ferritin $<100 \mu \mathrm{g} / \mathrm{L}$ or between 100 and $299 \mu \mathrm{g} / \mathrm{L}$ if the transferrin saturation was $<20 \%$ (haemoglobin was between 9.5 and $13.5 \mathrm{~g} / \mathrm{dL}$ ). The study showed improvements in functional status with improved self-reported patient global assessment at 24 weeks. ${ }^{64}$ However, it is unclear whether this confers a mortality benefit.

The Reduction of Events with Darbepoetin Alfa in Heart Failure trial evaluated treatment of anaemia using darbepoetin alfa in systolic heart failure. The study included patients with an average age of 72, with NYHA class II-IV symptoms, LVEF $<40 \%$ and $\mathrm{Hb} 9.0-12.0 \mathrm{~g} / \mathrm{dL}$ that were on guideline-directed therapy. The patients were randomised to darbepoetin alfa or matching placebo and the primary outcome was a composite death from any cause or first hospitalisation from worsening heart failure. The study did not show a statistically significant benefit with darbepoetin and there were more thrombotic and embolic events in the darbepoetin group. ${ }^{65}$ Currently, there are no recommendations by the ACC/AHA on the role of either iron or darbepoetin in the management of heart failure.

\section{Statins}

The data for use of statins in symptomatic heart failure are not robust because these patients are typically excluded from many of the RCTs. The theory for statin benefit in heart failure is thought to be related to the pleotropic effects of statins involving antiinflammatory activity and improvements in endothelial function.

The Controlled Rosuvastatin Multinational Trial in Heart Failure trial (CORONA) was an RCT of 5011 older patients ( $\geq 60$ years) with NYHA class II-IV (average EF 27\%) randomised to placebo or rosuvastatin. The primary outcome in this trial was a composite of death from cardiovascular disease, non-fatal MI or stroke. The rosuvastatin group had a reduction in low-density lipoprotein-cholesterol to $76 \mathrm{mg} / \mathrm{dL}$ at 3 months. ${ }^{66}$ Although, the HR for the primary outcome was 0.95 with no statistical significance, there was a significant decrease in hospitalisation for cardiovascular causes in the statin group. One of the limitations of this study was the use of older patients with more severe heart failure and likely suffered from advanced cardiovascular disease.

The Effect of rosuvastatin in patients with chronic heart failure trial (GISSI-HF) study was an RCT examining a broader range of patients with NYHA class II-IV with variable EF and aetiology. The primary outcome was time to death and time to death or admission to hospital for cardiovascular reasons. The study found no statistical difference with rosuvastatin on death or hospitalisation for cardiovascular reasons. ${ }^{67}$

A study pooled together data from the CORONA and GISSI-HF trials showed a reduction in MI of 19\% using rosuvastatin in patients with ischaemic heart failure.$^{68} \mathrm{It}$ is important to highlight that in the meta-analysis the absolute risk reduction was only $1.1 \%$ given the low number of MI. It is also important to consider the heterogeneity in pooling these patient populations given the very different population characteristics.

The ACC/AHA heart failure guidelines do not specifically address the role of statins in heart failure; however, the most recent updated ACC Consensus Committee does recommend statin in patients with ASCVD and NYHA class II-III heart failure due to ischaemic disease.

There may be some evidence to suggest the use of omega-2polyunsaturated fatty acid (PUFA) as therapy for heart failure. In GISSI-HF trial, investigators found a small significant reduction in death from any cause of $9 \% .{ }^{67}$ The ACC/AHA guideline suggests PUFA is reasonable to use adjunctive in patients with NYHA class II-IV.

\section{FUTURE DIRECTIONS \\ Ularitide}

Urodilatin is a human natriuretic peptide produced in the kidney by processing pro-ANP that aids in water and salt reabsorption. ${ }^{69-71} \mathrm{~A}$ synthetic form of urodilatin is ularitide, which has been shown to induce natriuresis, diuresis, vasodilation and inhibition of RAAS. ${ }^{72-74}$ Thus far, clinical trials prove

\section{Main messages}

- Natriuretic peptides have good prognostic implications. Elevated B-type natriuretic peptide has been associated with increased mortality and cardiovascular events in all patients with heart failure.

- Ivabradine has been approved by Food and Drug Administration for patients with chronic stable heart failure, with $\mathrm{EF}<35 \%$ who are unable to tolerate $\beta$-blockers or are on maximally tolerated $\beta$-blockers with a resting heart rate $>70$ bpm.

- Sacubitril/valsartan has the potential to inhibit two systems that lead to progression of heart failure and has been approved for heart failure treatment in patients with NYHA class II-IV with the goal to reduce mortality.

- No study has proven any mortality of benefit when using diuretics and currently they are recommended solely for symptomatic relief. However, there are some studies that suggest torsemide may reduce recurrent hospitalisations for decompensated heart failure compared with furosemide 
that it leads to vasodilation and lowers cardiac filling pressures. It is currently in phase III of the Trial of Ularitide's Efficacy and Safety in Patients with Acute Heart Failure, which examines symptoms and cardiovascular mortality in patients with acute decompensated heart failure. $^{74}$

\section{CONCLUSION}

Despite numerous advances in therapy, both pharmacological and implantable, heart failure continues to be a deadly disease accounting for up to one in nine deaths in the USA. Several therapies, including $\beta$-blockers, ACEI, aldosterone antagonists, hydralazineisosorbide dinitrate combinations have been mainstay therapy for decades. However, newer therapies such as sacubitril/valsartan, ivabradine and aliskiren have been shown to improve mortality and hospital readmission rates. Future directions likely include more pharmacological therapies as well as gene therapy hoping to reduce fatalities and improve quality of life of these patients.

\section{Current research questions}

- Heart failure and renin-angiotensin-aldosterone system have been closely linked for decades. Thus far, we have pharmacotherapies that inhibit both ACEI and ARB. However, there are several steps in the pathway that have not been able to be blocked. Can future directions of research focus on these different gateways?

- Natriuretic peptides play a vital role in heart failure. Most importantly, elevated values have been found in volume-overloaded states. Reviews have attempted to guide therapy based on its value, but there has been no consensus on its utility. Will trials in the future be able to investigate natriuretic-guided therapy in attempts to minimise readmissions and hospital length of stay?

- There are some data on combination or poly-pills emerging to treat cardiovascular disease. Some research shows that these may improve adherence and improve mortality. Given several pharmacotherapies that improve mortality in heart failure, is the next step in heart failure management the development of a poly-pill?

\section{Key references}

- Writing Committee M, Yancy CW, Jessup M, et al. 2013 ACCF/AHA guideline for the management of heart failure: a report of the American College of Cardiology Foundation/ American Heart Association Task Force on practice guidelines. Circulation 2013;128(16):e240-327.

- Fonarow GC, Peacock WF, Phillips CO, et al. Admission B-type natriuretic peptide levels and in-hospital mortality in acute decompensated heart failure. J Am Coll Cardiol 2007;49(19):1943-50.

- Felker GM, Lee KL, Bull DA, et al. Diuretic strategies in patients with acute decompensated heart failure. N Engl J Med 2011;364(9):797-805.

- Sacubitril/Valsartan (Entresto) for Heart Failure. JAMA 2015;314(7):722-3.

- Swedberg K, Komajda M, Bohm M, et al. Ivabradine and outcomes in chronic heart failure (SHIFT): a randomised placebo-controlled study. Lancet 2010;376(9744):875-85.

\section{Self assessment questions}

Please answer True or False to the below statements.

1. What pharmacological therapy has been shown to reduce mortality in patients with New York Heart Association (NYHA) class III-IV heart failure with reduced ejection fraction (HFrEF)?
A. Sacubitril/valsartan
B. Aliskiren
C. Furosemide

2. First-line therapy for HFrEF include all of the following except:
A. ACE inhibitor (ACEI) or angiotensin receptor blocker (ARB)
B. $\beta$-Blocker
C. Digoxin

3. Ivabradine is recommended for patients with chronic, symptomatic NYHA class II-III HFrEF who have all of the following except:
A. Ejection fraction (EF) $<35 \%$
B. Unable to tolerate $\beta$-blockers
C. Currently on $\beta$-blocker with resting heart rate $>90 \mathrm{bpm}$

4. Increased natriuretic peptides have been shown to be associated with
A. Increased cardiovascular events
B. Decreased mortality
C. Increased readmission rates for heart failure

5. According to the American College of Cardiology/American Heart Association guidelines, which calcium-channel blocker (CCB) has been associated with harm and therefore is not recommended?
A. Verapamil
B. Amlodipine
C. Nifedipine

Contributors LR and BA determined structure and content of the paper, LR wrote the paper, BA aided with editing and revising the paper.

Competing interests None declared.

Provenance and peer review Not commissioned; externally peer reviewed.

\section{REFERENCES}

1 Go AS, Mozaffarian D, Roger VL, et al. Heart disease and stroke statistics - 2013 update: a report from the American Heart Association. Circulation 2013;127: e6-245.

2 Roger VL. Epidemiology of heart failure. Circ Res 2013;113:646-59.

$3 \mathrm{Ni} \mathrm{H}, \mathrm{Xu}$ J. Recent trends in heart failure-related mortality: United States, 20002014. NCHS Data Brief 2015;(231):1-8.

4 Yancy CW, Jessup M, Bozkurt B, et al., WRITING COMMITTEE MEMBERS, American College of Cardiology Foundation/American Heart Association Task Force on Practice Guidelines. 2013 ACCF/AHA guideline for the management of heart failure: a report of the American College of Cardiology Foundation/American Heart Association Task Force on practice guidelines. Circulation 2013;128:e240-327.

5 Mentz RJ, O'Connor CM. Pathophysiology and clinical evaluation of acute heart failure. Nat Rev Cardiol 2016;13:28-35.

6 Udelson JE, Stevenson LW. The future of heart failure diagnosis, therapy, and management. Circulation 2016;133:2671-86

7 Schiff GD, Fung S, Speroff T, et al. Decompensated heart failure: symptoms, patterns of onset, and contributing factors. Am J Med 2003;114:625-30.

8 Fallick C, Sobotka PA, Dunlap ME. Sympathetically mediated changes in capacitance: redistribution of the venous reservoir as a cause of decompensation. Circ Heart Fail 2011;4:669-75.

9 Marti CN, Gheorghiade M, Kalogeropoulos AP, et al. Endothelial dysfunction, arterial stiffness, and heart failure. J Am Coll Cardiol 2012;60:1455-69.

10 Wang CS, FitzGerald JM, Schulzer M, et al. Does this dyspneic patient in the emergency department have congestive heart failure? JAMA 2005;294:1944-56. 
11 Zarrinkoub $R$, Wettermark $B$, Wändell $P$, et al. The epidemiology of heart failure, based on data for 2.1 million inhabitants in Sweden. Eur J Heart Fail 2013;15:995-1002.

12 Tsai SH, Lin YY, Chu SJ, et al. Interpretation and use of natriuretic peptides in non-congestive heart failure settings. Yonsei Med J 2010;51:151-63.

13 Doust JA, Pietrzak E, Dobson A, et al. How well does B-type natriuretic peptide predict death and cardiac events in patients with heart failure: systematic review. BMJ 2005:330:625.

14 Fonarow GC, Peacock WF, Phillips CO, et al. Admission B-type natriuretic peptide levels and in-hospital mortality in acute decompensated heart failure. J Am Coll Cardiol 2007:49:1943-50.

15 Troughton RW, Frampton CM, Brunner-La Rocca HP, et al. Effect of B-type natriuretic peptide-guided treatment of chronic heart failure on total mortality and hospitalization: an individual patient meta-analysis. Eur Heart J 2014;35:1559-67.

16 Daniels LB, Clopton P, Bhalla V, et al. How obesity affects the cut-points for B-type natriuretic peptide in the diagnosis of acute heart failure. Results from the Breathing Not Properly Multinational Study. Am Heart J 2006;151:999-1005.

17 Aune D, Sen A, Norat T, et al. Body mass index, abdominal fatness, and heart failure incidence and mortality: a systematic review and dose-response meta-analysis of prospective studies. Circulation 2016;133:639-49.

18 Piepoli MF, Davos C, Francis DP, et al. Exercise training meta-analysis of trials in patients with chronic heart failure (ExTraMATCH). BMJ 2004;328:189.

19 Ades PA, Keteyian SJ, Balady GJ, et al. Cardiac rehabilitation exercise and self-care for chronic heart failure. JACC Heart Fail 2013;1:540-7.

20 Effects of enalapril on mortality in severe congestive heart failure. Results of the Cooperative North Scandinavian Enalapril Survival Study (CONSENSUS). The CONSENSUS Trial Study Group. N Engl J Med 1987;316:1429-35.

21 Effect of enalapril on survival in patients with reduced left ventricular ejection fractions and congestive heart failure. The SOLVD Investigators. N Engl I Med 1991;325:293-302

22 Cohn JN, Tognoni G, Valsartan Heart Failure Trial Investigators. A randomized trial of the angiotensin-receptor blocker valsartan in chronic heart failure. N Engl J Med 2001:345:1667-75.

23 Hjalmarson A, Goldstein S, Fagerberg B, et al. Effects of controlled-release metoprolol on total mortality, hospitalizations, and well-being in patients with heart failure: the Metoprolol CR/XL Randomized Intervention Trial in congestive heart failure (MERIT-HF). MERIT-HF Study Group. JAMA 2000;283:1295-302.

24 Packer $M$, Coats $A J$, Fowler MB, et al. Effect of carvedilol on survival in severe chronic heart failure. N Engl J Med 2001:344:1651-8.

25 Packer M, Bristow MR, Cohn JN, et al. The effect of carvedilol on morbidity and mortality in patients with chronic heart failure. U.S. Carvedilol Heart Failure Study Group. N Engl J Med 1996;334:1349-55.

26 A randomized trial of beta-blockade in heart failure. The Cardiac Insufficiency Bisoprolol Study (CIBIS). CIBIS Investigators and Committees. Circulation 1994;90:1765-73.

27 The Cardiac Insufficiency Bisoprolol Study II (CIBIS-II): a randomised trial. Lancet 1999:353:9-13.

28 Mizuno $\mathrm{Y}$, Yoshimura $\mathrm{M}$, Yasue $\mathrm{H}$, et al. Aldosterone production is activated in failing ventricle in humans. Circulation 2001:103:72-7.

29 Harada $\mathrm{E}$, Yoshimura $\mathrm{M}$, Yasue $\mathrm{H}$, et al. Aldosterone induces angiotensin-converting-enzyme gene expression in cultured neonatal rat cardiocytes. Circulation 2001;104:137-9.

30 Taylor AL, Ziesche S, Yancy C, et al. Combination of isosorbide dinitrate and hydralazine in blacks with heart failure. N Engl J Med 2004;351:2049-57.

31 Taylor AL, Ziesche S, Yancy CW, et al. Early and sustained benefit on event-free survival and heart failure hospitalization from fixed-dose combination of isosorbide dinitrate/hydralazine: consistency across subgroups in the African-American Heart Failure Trial. Circulation 2007;115:1747-53.

32 Rahimtoola SH. Digitalis therapy for patients in clinical heart failure. Circulation 2004:109:2942-6.

33 Smith TW. Digitalis. Mechanisms of action and clinical use. N Eng/ J Med 1988:318:358-65.

34 McMahon WS, Holzgrefe HH, Walker JD, et al. Cellular basis for improved left ventricular pump function after digoxin therapy in experimental left ventricular failure. J Am Coll Cardiol 1996;28:495-505.

35 Digitalis Investigation $\mathrm{G}$. The effect of digoxin on mortality and morbidity in patients with heart failure. N Engl J Med 1997:336:525-33.

36 Peacock WF 4th, Fonarow GC, Emerman CL, et al. Impact of early initiation of intravenous therapy for acute decompensated heart failure on outcomes in ADHERE. Cardiology 2007;107:44-51.

37 Felker GM, Lee $\mathrm{KL}$, Bull DA, et al. Diuretic strategies in patients with acute decompensated heart failure. N Engl J Med 2011;364:797-805.

38 DiNicolantonio JJ. Should torsemide be the loop diuretic of choice in systolic heart failure? Future Cardiol 2012:8:707-28.

39 Sonnenblick EH, Frishman WH, LeJemtel TH. Dobutamine: a new synthetic cardioactive sympathetic amine. N Engl J Med 1979;300:17-22.
40 Ruffolo RR, Jr. The pharmacology of dobutamine. Am J Med Sci 1987;294:244-8.

41 Stevenson LW. Clinical use of inotropic therapy for heart failure: looking backward or forward? Part II: chronic inotropic therapy. Circulation 2003;108:492-7.

42 Guglin M, Kaufman M. Inotropes do not increase mortality in advanced heart failure. Int J Gen Med 2014;7:237-51.

43 Elkayam U, Tasissa G, Binanay C, et al. Use and impact of inotropes and vasodilator therapy in hospitalized patients with severe heart failure. Am Heart J 2007:153:98-104.

44 Abraham WT, Adams KF, Fonarow GC, et al. In-hospital mortality in patients with acute decompensated heart failure requiring intravenous vasoactive medications: an analysis from the Acute Decompensated Heart Failure National Registry (ADHERE) J Am Coll Cardiol 2005;46:57-64.

45 Vardeny 0 , Miller R, Solomon SD. Combined neprilysin and renin-angiotensin system inhibition for the treatment of heart failure. JACC Heart Fail 2014;2:663-70.

46 Sacubitril/Valsartan (Entresto) for heart failure. JAMA 2015:314:722-3.

47 von Lueder TG, Sangaralingham SJ, Wang BH, et al. Renin-angiotensin blockade combined with natriuretic peptide system augmentation: novel therapeutic concepts to combat heart failure. Circ Heart Fail 2013;6:594-605.

48 McMurray JJ, Packer M, Desai AS, et al. Angiotensin-neprilysin inhibition versus enalapril in heart failure. N Engl J Med 2014;371:993-1004.

49 Lechat $\mathrm{P}$, Hulot JS, Escolano $\mathrm{S}$, et al. Heart rate and cardiac rhythm relationships with bisoprolol benefit in chronic heart failure in CIBIS II trial. Circulation 2001;103:1428-33.

50 McAlister FA, Wiebe N, Ezekowitz JA, et al. Meta-analysis: beta-blocker dose, heart rate reduction, and death in patients with heart failure. Ann Intern Med 2009;150:784-94.

51 Ferrari R, Ford I, Fox K, et al., Beautiful Study Group. The BEAUTIFUL study: randomized trial of ivabradine in patients with stable coronary artery disease and left ventricular systolic dysfunction-baseline characteristics of the study population. Cardiology 2008;110:271-82

52 Opdahl A, Ambale Venkatesh B, Fernandes VR, et al. Resting heart rate as predicto for left ventricular dysfunction and heart failure: MESA (Multi-Ethnic Study of Atherosclerosis). J Am Coll Cardiol 2014;63:1182-9.

53 Chaudhary R, Garg J, Krishnamoorthy P, et al. Ivabradine: heart failure and beyond. J Cardiovasc Pharmacol Ther 2016;21:335-43.

54 Savelieva I, Camm AJ. I f inhibition with ivabradine: electrophysiological effects and safety. Drug Saf 2008;31:95-107.

55 Swedberg K, Komajda M, Böhm M, et al. Ivabradine and outcomes in chronic heart failure (SHIFT): a randomised placebo-controlled study. Lancet 2010;376:875-85.

56 Latini R, Masson S, Anand I, et al. The comparative prognostic value of plasma neurohormones at baseline in patients with heart failure enrolled in Val-HeFT. Eur Heart J 2004;25:292-9.

57 Gheorghiade M, Böhm M, Greene SJ, et al. Effect of aliskiren on postdischarge mortality and heart failure readmissions among patients hospitalized for heart failure: the ASTRONAUT randomized trial. JAMA 2013;309:1125-35.

58 McMurray JJ, Krum H, Abraham WT, et al. Aliskiren, enalapril, or aliskiren and enalapril in heart failure. N Engl J Med 2016;374:1521-32.

59 Page RL 2nd, O'Bryant CL, Cheng D, et al. Drugs that may cause or exacerbate heart failure: a scientific statement from the American Heart Association. Circulation 2016;134:e32-69.

60 Packer M, O'Connor CM, Ghali JK, et al. Effect of amlodipine on morbidity and mortality in severe chronic heart failure. Prospective Randomized Amlodipine Survival Evaluation Study Group. N Engl J Med 1996;335:1107-14.

61 Massie BM, Collins JF, Ammon SE, et al. Randomized trial of warfarin, aspirin, and clopidogrel in patients with chronic heart failure: the Warfarin and Antiplatelet Therapy in Chronic Heart Failure (WATCH) trial. Circulation 2009;119:1616-24.

62 Homma S, Thompson JL, Pullicino PM, et al. Warfarin and aspirin in patients with heart failure and sinus rhythm. N Engl J Med 2012;366:1859-69.

63 Groenveld HF, Januzzi JL, Damman K, et al. Anemia and mortality in heart failure patients a systematic review and meta-analysis. J Am Coll Cardiol 2008;52:818-27.

64 Anker SD, Comin Colet J, Filippatos G, et al. Ferric carboxymaltose in patients with heart failure and iron deficiency. N Engl J Med 2009;361:2436-48.

65 Swedberg K, Young JB, Anand IS, et al. Treatment of anemia with darbepoetin alfa in systolic heart failure. N Engl J Med 2013;368:1210-19.

66 Rogers JK, Jhund PS, Perez AC, et al. Effect of rosuvastatin on repeat heart failure hospitalizations: the CORONA Trial (Controlled Rosuvastatin Multinational Trial in Heart Failure). JACC Heart Fail 2014;2:289-97.

67 Tavazzi L, Maggioni AP, Marchioli R, et al. Effect of rosuvastatin in patients with chronic heart failure (the GISSI-HF trial): a randomised, double-blind, placebo-controlled trial. Lancet 2008:372:1231-9.

68 Feinstein MJ, Jhund P, Kang J, et al. Do statins reduce the risk of myocardial infarction in patients with heart failure? A pooled individual-level reanalysis of CORONA and GISSI-HF. Eur J Heart Fail 2015;17:434-41.

69 Goetz KL. Renal natriuretic peptide (urodilatin?) and atriopeptin: evolving concepts. Am J Physiol 1991;261(6 Pt 2):F921-32. 
70 Forssmann WG, Richter R, Meyer M. The endocrine heart and natriuretic peptides: histochemistry, cell biology, and functional aspects of the renal urodilatin system. Histochem Cell Biol 1998;110:335-57.

71 Saba SR, Ramirez G, Vesely DL. Immunocytochemical localization of ProANF 1-30, ProANF 31-67, atrial natriuretic factor and urodilatin in the human kidney. Am J Nephrol 1993;13:85-93.

72 Carstens J, Jensen KT, Pedersen EB. Effect of urodilatin infusion on renal haemodynamics, tubular function and vasoactive hormones. Clin Sci 1997;92:397-407.

73 Flüge $\mathrm{T}$, Fabel $\mathrm{H}$, Wagner TO, et al. Urodilatin (ularitide, INN): a potent bronchodilator in asthmatic subjects. Eur J Clin Invest 1995;25:728-36.

74 Anker SD, Ponikowski P, Mitrovic V, et al. Ularitide for the treatment of acute decompensated heart failure: from preclinical to clinical studies. Eur Heart $J$ 2015;36:715-23.

\section{Answers}

1 A. True. Based on Prospective Comparison of ARNI with ACEI to Determine Impact on Global Mortality and Morbidity in Heart Failure study

B. False. Thus far, randomised controlled trials have had mixed results, including Aliskiren Trial on Acute Heart Failure Outcomes and Aliskiren Trial to Minimize Outcomes in Patients with Heart Failure

C. False. Has not been shown to reduce mortality. It is only given for symptom management

2 A. True. Based on current guidelines

B. True. Based on current guidelines

C. False. Proven to reduce clinical symptoms, but not currently first-line therapy

3 A. True

B. True

C. False

4 A. True

B. False

C. False

5 A. True. Non-dihydropyridine CCB which negative chronotropic effect

B. False

C. False 